\title{
Overexpression of ROD1 inhibits invasion of breast cancer cells by suppressing the translocation of $\beta$-catenin into the nucleus
}

\author{
YA ZHOU*, HANQING ZOU*, ENHAO WU, LEI HUANG, RUI YIN, YUXIN MEI and XUN ZHU \\ Department of General Surgery, The Second Affiliated Hospital of Soochow University, Suzhou, Jiangsu 215004, P.R. China
}

Received July 2, 2017; Accepted April 16, 2018

DOI: $10.3892 / \mathrm{ol} .2018 .8917$

\begin{abstract}
The incidence of breast cancer is increasing throughout the world. Although significant progress has been made in diagnostic techniques and targeted therapies, the prognosis of breast cancer remains poor. Regulator of differentiation 1 (ROD1) may inhibit the development of several types of cancer. However, the role of ROD1 in breast cancer cells remains unknown. In the present study, western blot analysis and reverse transcription-quantitative polymerase chain reaction revealed that expression of ROD1 was significantly reduced in breast cancer cells. Overexpression of ROD1 reduced the proliferation rate, demonstrated using a Cell Counting Kit-8 assay. Additionally, the overexpression of ROD1 decreased the invasiveness of breast cancer cells, indicating that ROD1 may serve as a tumor suppressor. Additionally, the data suggested that ROD1 significantly suppressed the activity of Wnt luciferase reporter (TOP Flash) in MDA-MB-231 cells. Furthermore, it was demonstrated that ROD1 may interact with $\beta$-catenin by using co-immunoprecipitation, resulting in suppression of $\beta$-catenin migration into the nucleus. Notably, ROD1 demonstrated its anticancer effect by decreasing $\beta$-catenin (Y333) phosphorylation in a nude mouse xenograft model. Overexpression of ROD1 may downregulate Ki67 protein levels, as determined by immunohistochemistry. These results indicated that ROD1 may be used as a therapeutic target in patients with breast cancer.
\end{abstract}

\section{Introduction}

Breast cancer is the main cause of cancer-associated mortality in women globally (1). Significant progress has been made in diagnostic techniques and targeted therapies, however, the

Correspondence to: Mrs. Xun Zhu, Department of General Surgery, The Second Affiliated Hospital of Soochow University, 1055 Sanxiang Road, Suzhou, Jiangsu 215004, P.R. China

E-mail: xunzhusdfey1023@126.com

*Contributed equally

Key words: breast cancer, invasion, regulator of differentiation 1, Wnt/ $\beta$-catenin, nude mouse xenograft model prognosis of breast cancer remains poor (1). Therefore, it is important to identify the underlying molecular mechanisms in breast cancer. Various studies indicated that the activated Wnt/ $\beta$-catenin signaling pathway serves an essential role in tumorigenesis $(2,3)$ and $\sim 40 \%$ cases of breast cancer exhibit increased expression levels of $\beta$-catenin (4). It has been demonstrated that the $\mathrm{Wnt} / \beta$-catenin signaling pathway is regulated by cytosolic $\beta$-catenin, which may translocate into the nucleus to interact with transcriptional factors of the T-cell factor/lymphoid-enhancing factor (TCF/LEF) family resulting in activation of Wnt target genes (2-6). It is known that the downstream targets of $\beta$-catenin/TCF, including cyclin D1 and c-Myc, are vital regulators of cell proliferation and apoptosis and are associated with several types of cancer including mammary gland carcinogenesis, thyroid carcinogenesis and prostate cancer (7-9). Additionally, Wnt binds to a frizzled receptor in existence of the co-receptor, low density lipoprotein-related protein $5 / 6$, thus inhibiting $\beta$-catenin degradation (4). Furthermore, cytoplasmic $\beta$-catenin forms a complex with axis inhibition protein, adenomatosis polyposis coli, casein kinase 1 (CK1) and glycogen synthase kinase-3 $\beta$ (GSK-3 $\beta$ ) when Wnt is absent. Notably, cytoplasmic $\beta$-catenin is phosphorylated by $\mathrm{CK} 1$ and GSK-3 $\beta$ at the N-terminal region, leading to degradation of $\beta$-catenin through the ubiquitination proteasome pathway (10). Consequently, the Wnt signaling pathway is a potential therapeutic target in breast cancer (2-4).

Regulator of differentiation (ROD)1, also termed polypyrimidine tract binding protein 3 , was initially regarded as an inhibitor of cell differentiation (11). Overexpression of ROD1 was demonstrated to block phorbol ester and sodium butyrate-induced differentiation of K562 cells (11). Subsequently, it has been revealed that ROD1 is a member of the heterogeneous nuclear ribonucleoproteins family and participates in alternative splicing of pre-mRNA (12), a post-transcriptional regulation for gene expression (13). Additionally, abnormal splicing holds a vital role in various types of cancer (14). As a RNA-binding protein, ROD1 binds to the post-transcriptional RNA of $>10^{4}$ genes associated with the differentiation and proliferation of cancer cells detected by RNA immunoprecipitation-sequencing (15). Notably, ROD1 may promote proliferation but inhibit the differentiation of human gastric cancer MKN45 cells (16). However, it remains unknown whether ROD1 expression is aberrant in breast cancer, and whether it serves an essential role in the proliferation and invasion of breast cancer cells. 
In the present study, ROD1 expression was analyzed by western blotting and reverse transcription-quantitative polymerase chain reaction (RT-qPCR) in normal and cancer tissues. The effects of ROD1 on invasion of breast cancer cells as well as tumor growth were investigated in a xenograft model. Finally, the aim of this study was to investigate the molecular mechanism of ROD1 in breast cancer cell invasion.

\section{Materials and methods}

Cell culture. The human breast cancer cells (MCF-7 and MDA-MB-231), normal cells (hMC and MCF10A) and 293A cells were purchased from ATCC (American Type Culture Collection; Manassas, VA, USA). These cells were maintained in RPMI-1640 medium (Gibco; Thermo Fisher Scientific, Inc., Waltham, MA, USA) containing 10\% fetal bovine serum (FBS; Gibco; Thermo Fisher Scientific, Inc.), $100 \mathrm{U} / \mathrm{ml}$ penicillin and $100 \mathrm{mg} / \mathrm{ml}$ streptomycin which were obtained from Gibco; Thermo Fisher Scientific, Inc. Subconfluent cells were treated with adriamycin (Sigma-Aldrich; Merck KGaA, Darmstadt, Germany) diluted into the medium to a final concentration of $1.5 \mathrm{mg} / \mathrm{ml}$. All cells were placed in a humidified incubator containing $5 \%$ $\mathrm{CO}_{2}$ and $95 \%$ air at $37^{\circ} \mathrm{C}$.

Cell proliferation. Cell proliferation rate was examined by Cell Counting Kit-8 (CCK-8) (Sigma-Aldrich; Merck KGaA), according to the manufacturer's protocol at the given time points $(0,12,24,36$ and 48 h). In brief, MDA-MB-231 cells were seeded in 96-well plates at a density of $\sim 2 \times 10^{3}$ cells/well and maintained in RPMI-1640 medium. Subsequently, the testing reagent $(10 \mu \mathrm{l})$ was added to each well at $37^{\circ} \mathrm{C}$ for $2 \mathrm{~h}$. The optical absorption $(450 \mathrm{~nm})$ of each well was detected using a microplate reader. The adenoviruses were diluted with RPMI-1640 medium at a final concentration of $2 \times 10^{2}$ for each well. These cells were transfected with adenovirueses, Ad-vector, Ad-ROD1 and Ad-shROD1 (Hanbio Biotechnology Co., Ltd., Shanghai, China) for $12 \mathrm{~h}$ at $37^{\circ} \mathrm{C}$. Then, the adenovirus containing medium was removed and fresh medium was added to the wells. Following transfection for another $0,12,24,36$ and $48 \mathrm{~h}$, the transfected MDA-MB-231 cell proliferation was determined by CCK-8 assay. The group 'con' (Fig. 1) represents the negative control, with cells that did not undergo transfection. The experiment was repeated three times.

Cell invasion. In order to measure the invasiveness of MDA-MB-231 cells, these were plated in Transwell plates ( $8.0 \mu \mathrm{m}$ pore size; Corning Inc., NY, USA) coated with Matrigel (Sigma-Aldrich; Merck KGaA). Briefly, $5 \times 10^{4}$ cells/well were placed in the upper chamber in RPMI-1640 with no serum; the lower chamber was filled with RPMI-1640 (supplemented with $10 \% \mathrm{FBS}$ ). Following incubation at $37^{\circ} \mathrm{C}$ for $48 \mathrm{~h}$, the cells in lower chamber were fixed with $4 \%$ paraformaldehyde at $4^{\circ} \mathrm{C}$ for $1 \mathrm{~h}$, and stained with $0.1 \%$ crystal violet at $4^{\circ} \mathrm{C}$ for $1 \mathrm{~h}$, extracted with $33 \%$ acetic acid and the absorbance was measured at a wavelength of $570 \mathrm{~nm}$ using a microplate reader. Paraformaldehyde, crystal violet and acetic acid were obtained from Sigma-Aldrich; Merck KGaA. The experiment was repeated three times.
RNA isolation, $c D N A$ synthesis and RT-qPCR. Total RNA was isolated from cells or tissues using TRIzol reagent (Thermo Fisher Scientific, Inc.). Subsequently, cDNA synthesis was performed using the Superscript III RT kit (Thermo Fisher Scientific, Inc.). RT-qPCR reactions were carried out using the SYBR Green PCR Master Mix (Thermo Fisher Scientific, Inc.) in an ABI 7500 thermal cycler (Thermo Fisher Scientific, Inc.). GAPDH was used as an internal control. The primers used were as follows: GAPDH, sense, 5'-CACCATCTTCCA GGAGCGAG-3' and antisense, 5'-GCAGGAGGCATTGCT GAT-3'; ROD1, sense, 5'-CACCTTTCTCTCTCCCCAAGA AACT-3' and antisense, 5'-TTGCTGTCATTCCCATTAGCT GT-3' (Invitrogen; Thermo Fisher Scientific, Inc.). The thermocycling conditions were as follows: Initial denaturation of $94^{\circ} \mathrm{C}$ for $5 \mathrm{~min}$, followed by 40 cycles of $94^{\circ} \mathrm{C}$ for $30 \mathrm{sec}$ and $58^{\circ} \mathrm{C}$ for $30 \mathrm{sec}$, and final extension of $72^{\circ} \mathrm{C}$ for $15 \mathrm{sec}$. Each reaction was conducted in duplicate. Relative mRNA expression of ROD1 gene was evaluated using the $2^{-\triangle \Delta C q}$ method (17).

Construction of recombinant adenoviral vectors (Ad)-RODI and Ad-short hairpin(sh)ROD1. The primers for human ROD1 gene were as follows: sense, 5'-ATGCCTTTCTCTCTCCCC AAGAAACT-3' and antisense, 5'-TCAGATTGTAGATTT TGAGAAGGAA-3' (Invitrogen; Thermo Fisher Scientific, Inc.), and restriction digestion enzymes $X b a \mathrm{I}$ and $K p n \mathrm{I}$ (Thermo Fisher Scientific, Inc.) were used for cloning this gene. The PCR-amplified fragments were used for subcloning into the pAdEasy/Track-cytomegalovirus (CMV) vector (Stratagene; Agilent Technologies, Inc., Santa Clara, CA, USA). The targeting sequence of shROD1 was 5'-GCCCTG TGCTTCGAATAAT-3' (Invitrogen; Thermo Fisher Scientific, Inc.). The interfering RNA of ROD1 was subcloned into the pAdEasy/Track-CMV vector with HindIII and $K p n I$ (Thermo Fisher Scientific, Inc.). DNA polymerase, restrictive enzymes and T4 ligase were purchased from Thermo Fisher Scientific, Inc. The ligation reaction mixture was prepared as follows: 100-500 ng Linear DNA, 1-2 $\mu \mathrm{g}$ phosphorylated linkers, $2 \mu \mathrm{l}$ 10X T4 DNA Ligase buffer, $2 \mu 1$ 50\% PEG 4000 solution, 2 U T4 DNA Ligase, with nuclease-free water to $20 \mu \mathrm{l}$. The agents were mixed thoroughly and incubated for $1 \mathrm{~h}$ at $22^{\circ} \mathrm{C}$ and then the reaction was subjected to heat-inactivation at $65^{\circ} \mathrm{C}$ for $10 \mathrm{~min}$ or at $70^{\circ} \mathrm{C}$ for $5 \mathrm{~min}$. Finally, the products were used for transfecting competent bacteria. Additionally, shScramble adenoviral vectors were not used in this study, and instead the Track-CMV empty vector was used as the control. The plasmids were transfected into 293A packaging cells using Lipofectamine ${ }^{\circledR} 2000$ (Invitrogen; Thermo Fisher Scientific, Inc.) to generate recombinant adenoviruses. Subsequently, viral particles were purified using cesium chloride density gradient ultracentrifugation $\left(120,000 \mathrm{xg}\right.$ for $20 \mathrm{~h}$ at $\left.4^{\circ} \mathrm{C}\right)(18)$. The titer of virus was examined by RT-qPCR $(19,20)$. A negative control virus (Ad-Vector) was used.

Luciferase reporter assay. To determine luciferase of

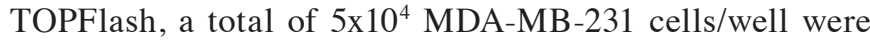
plated in 24-well plates. TOPFlash plasmid (Add gene, Inc., Cambridge, MA, USA) is a firefly luciferase reporter with wild type TCF/LEF binding sites (21-24). FOPFlash plasmid with mutant TCF/LEF binding sites often functions as a control for background luminescence (21-24). The ratio of the luciferase 
A

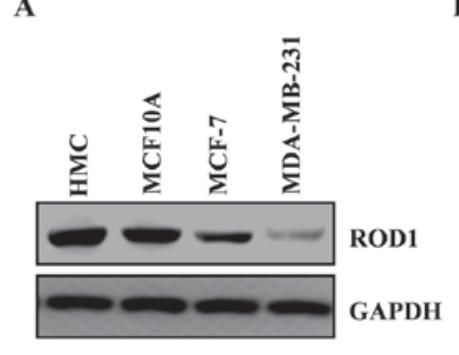

D

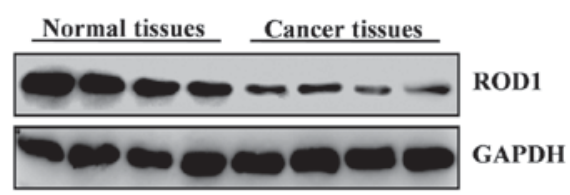

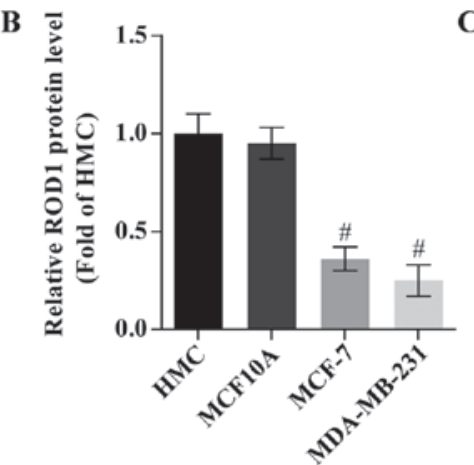
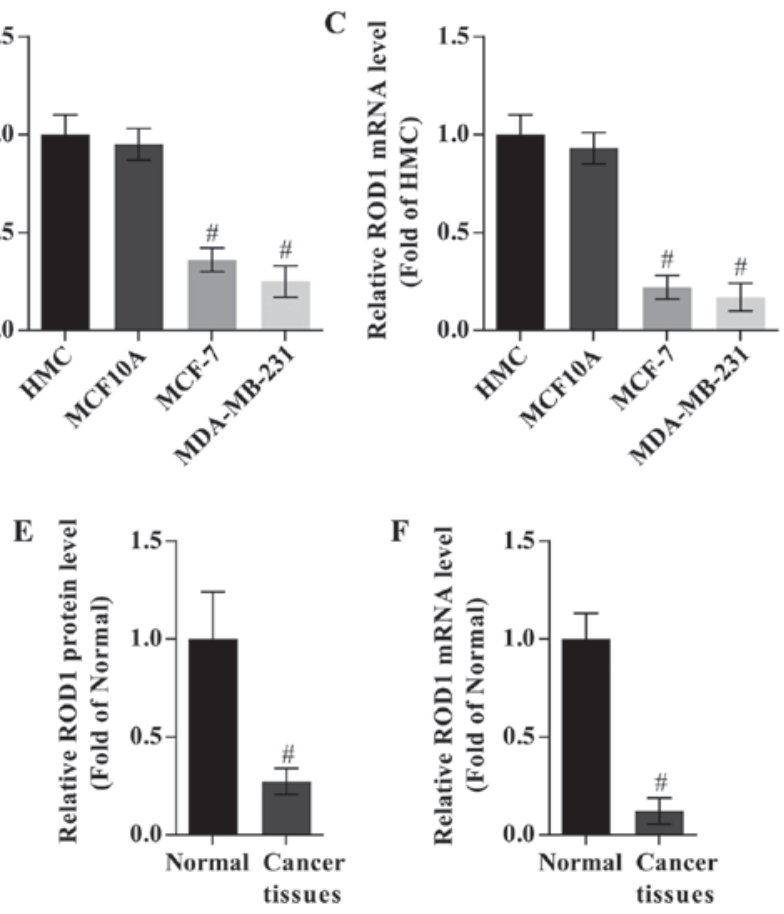

Figure 1. Expression of ROD1 is lower in breast cancer cells and tissues. (A) Analysis of (B) protein and (C) mRNA expression levels of ROD1 in MCF-7 and MDA-MB-231 (breast cancer cells) compared with HMC and MCF10A. (D) Analysis of (E) protein and (F) mRNA expression levels of ROD1 in cancer tissues of TA2 mice with spontaneous breast cancer compared with normal tissues. ${ }^{~} \mathrm{P}<0.05$ vs. normal tissues $(\mathrm{n}=4)$. ROD1, regulator of differentiation 1.

activity of TOPflash against that of FOP flash was evaluated. A total of $0.5 \mu \mathrm{g}$ TOPFlash or FOPFlash plasmid was transfected/well. The un transfected cells were used as a control. Firefly luciferase activity was normalized for transfection efficiency using the corresponding Renilla luciferase activity. Following $12 \mathrm{~h}$ incubation with Ad-ROD1 or Ad-shROD1, the luciferase activity was determined using a Dual Luciferase ${ }^{\circledR}$ Reporter Assay kit (Promega Corporation, Madison, WI, USA), according to the manufacturer's protocol.

Western blot analysis and co-immunoprecipitation. Tissues and cells were lysed using a radioimmunoprecipitation assay (RIPA) buffer (cat no. P1003; Beyotime Institute of Biotechnology, Haimen, China) followed by centrifugation $\left(15,000 \mathrm{x} \mathrm{g}\right.$ for $30 \mathrm{~min}$ at $\left.4^{\circ} \mathrm{C}\right)$. In addition, nuclear and cytoplasmic extraction was performed according to the manufacturer's protocol (NE-PER ${ }^{\circledR}$ Nuclear and Cytoplasmic extraction reagents; Pierce Biotechnology; Thermo Fisher Scientific, Inc.). The protein concentration was determined by BCA Protein Quantification Kit (Thermo Fisher Scientific, Inc.). A total of $40 \mathrm{mg}$ protein for western blot analysis was separated in $10 \%$ TruPAGE $^{\mathrm{TM}}$ precast gels (Sigma-Aldrich; Merck KGaA) and transferred to a polyvinylidene difluoride (PVDF) membrane (Sigma-Aldrich; Merck KGaA). Subsequently, the membrane was blocked with 5\% skim milk (Sangon Biotech Co., Ltd., Shanghai, China) and incubated with primary antibodies at $4^{\circ} \mathrm{C}$ overnight and incubated with horseradish peroxidase (HRP)-conjugated goat anti-mouse and HRP-conjugated goat anti-rabbit secondary antibodies for $2 \mathrm{~h}$ at room temperature (BS12478 or BS13278; 1:5,000; Bio world Technology, Inc., St. Louis Park, MN, USA). GAPDH was used as an internal control. In the present study, the primary antibodies used were as follows: anti-ROD1 (14027-1-AP;
1:1,000; ProteinTech Group, Inc., Chicago, IL, USA), anti-GAPDH (SAB2701826; 1:1,000 dilution; Sigma-Aldrich; Merck KGaA), anti- $\beta$-catenin (9562; 1:1,000; Cell Signaling Technology, Inc., Danvers, MA, USA), anti- $\beta$-catenin (Y333; 11574, 1:1,000; AbSci, Vancouver, WA, USA), anti-lumin B (13435; 1:1,000; Cell Signaling Technology, Inc.), anti-c-Myc (9402; 1:1,000; Cell Signaling Technology, Inc.). Finally, the bands were detected using an enhanced chemiluminescence (ECL) Reagent Plus kit (Cell Signaling Technology, Inc.). The corresponding semi-quantitative analysis was based on optical density using Image J software (version 2.1.4.6; National Institutes of Health, Bethesda, MD, USA).

For the co-immunoprecipitation, cells or tissues were extracted using RIPA buffer (cat no. P1003; Beyotime Institute of Biotechnology). Supernatants were obtained by centrifugation $\left(15,000 \mathrm{x} \mathrm{g}, 15 \mathrm{~min}, 4^{\circ} \mathrm{C}\right)$ and incubated with the indicated antibodies (anti-ROD1) for $6 \mathrm{~h}$ at $4^{\circ} \mathrm{C}$ followed by immunoprecipitation with $30 \mathrm{ml}$ protein $\mathrm{A} / \mathrm{G}$ agarose (Thermo Fisher Scientific, Inc.). The precipitates were completely washed with PBS and evaluated by western blotting, as aforementioned.

Knockdown of $\beta$-catenin by small interfering RNA (siRNA) transfection. Knockdown of $\beta$-catenin by siRNA transfection was conducted in MDA-MB-231 cells using Lipofectamine ${ }^{\circledR}$ 2000 transfection reagent (Thermo Fisher Scientific, Inc.). The sequence of siRNA against $\beta$-catenin was 5'-UGGAUUUGU ACCAUUCUUCUG-3'. Subsequent to transfection at $37^{\circ} \mathrm{C}$ for $6 \mathrm{~h}$, the cells were maintained in fresh RPMI-1640 media for another $24 \mathrm{~h}$. Then, the cells were incubated with Ad-vector, Ad-ROD1 $\left(2 \times 10^{2}\right.$ plaque forming unit/well in 6-well plate, labeled as Ad-ROD1 L; $2 \times 10^{3}$ plaque forming unit/well, labeled as Ad-ROD1 $\mathrm{H}$ ) at $37^{\circ} \mathrm{C}$ for $24 \mathrm{~h}$. Finally, these cells were harvested for proliferation analysis and western blot analysis. 
$\mathbf{A}$

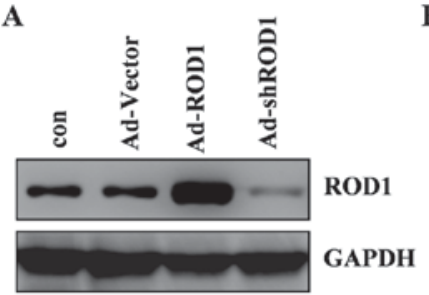

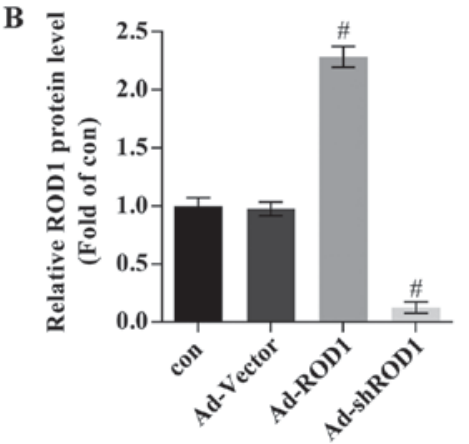
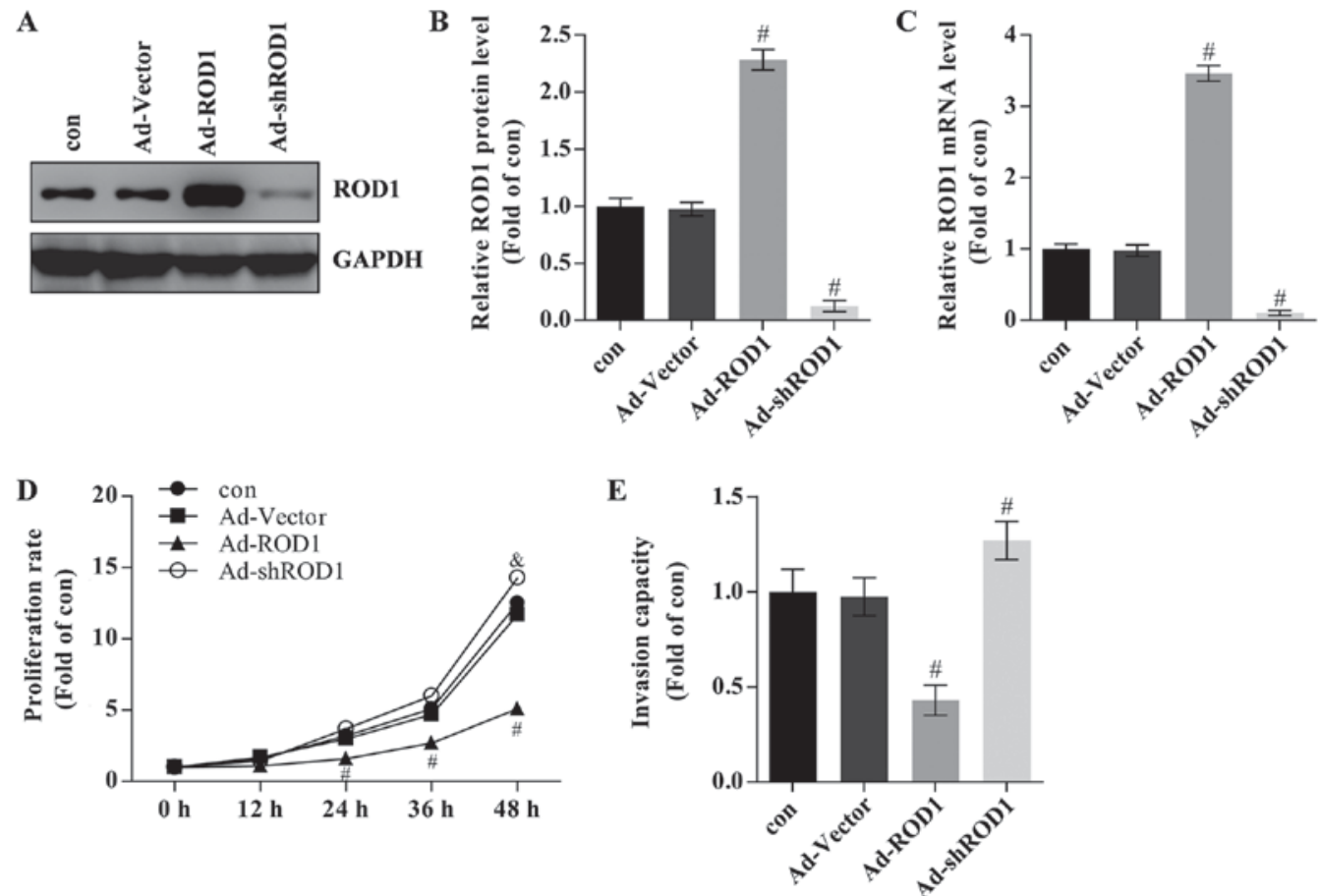

Figure 2. ROD1 inhibited cell growth and invasion in MDA-MB-231 cells. (A) Western blot analysis of ROD1 in MDA-MB-231 cells transfected with adenovirus overexpressing ROD1 (Ad-ROD1) and small interfering ROD1 (Ad-shROD1) and (B) quantification of its protein levels. (C) Quantification of mRNA levels of ROD1 in MDA-MB-231 cells transfected with Ad-ROD1 and Ad-shROD1. (D) Proliferation assay was conducted in MDA-MB-231 cells transfected with Ad-ROD1 and Ad-shROD1. All values are relative to the control at $0 \mathrm{~h}$. (E) Transwell analysis was conducted to detect invasiveness in MDA-MB-231 cells transfected with Ad-ROD1 and Ad-shROD1. ${ }^{~} \mathrm{P}<0.05$ vs. Ad-vector group. All experiments were replicated three times. Con, without adenovirus incubation; Ad, adenovirus; ROD1, regulator of differentiation 1; sh, short hairpin.

Immunohistochemistry. Breast cancer tissues and normal mammary tissues were fixed in $10 \%$ formalin buffer at $4^{\circ} \mathrm{C}$ for $24 \mathrm{~h}$. The fresh samples were immediately stored in liquid nitrogen $\left(\sim-200^{\circ} \mathrm{C}\right)$. The $10 \mu \mathrm{m}$ sections were subjected to dewaxing in xylene at room temperature for $15 \mathrm{~min}$ and dehydration in 95 and $80 \%$ graded ethanol at room temperature for $5 \mathrm{~min}$. Activity of endogenous peroxidase was blocked by $3 \% \mathrm{H}_{2} \mathrm{O}_{2}$ at room temperature for $10 \mathrm{~min}$. The sections were then heated to $100^{\circ} \mathrm{C}$ in $0.1 \mathrm{M}$ citrate buffer ( $\mathrm{pH}$ 6.0) for half an hour to retrieve the antigens. These tissues were incubated with anti-Ki-67 for overnight at $4^{\circ} \mathrm{C}$. Subsequent to washing with PBS three times, tissues were incubated with secondary antibodies at room temperature for $1 \mathrm{~h}$, which were horseradish peroxidase-conjugated anti-rabbit or anti-mouse IgG used according to the manufacturer's protocol. Finally, sections were stained with hematoxylin at room temperature for $10 \mathrm{~min}$. The stained tissues were photographed using a light microscope at x200 magnification from Carl Zeiss (Axio Observer A1; Carl Zeiss AG, Oberkochen, Germany). Ki67 antibody was obtained from Bioworld (cat no. BS9931M; 1:100). The secondary antibody was also obtained from Bioworld (cat no. BS13278; 1:1,000). In addition, diaminobenzidine (DAB; Beyotime Institute of Biotechnology) solution was applied for color development.

Mouse xenograft model. In the present study, five-week old female BALB/c nude (Nanjing Biomedical Research Institute of Nanjing University, Nanjing, China) were used and the mean weight of these mice were $17.03 \mathrm{~g}$. Mice were maintained at $25^{\circ} \mathrm{C}$ with a humidity of $\sim 50 \%$ and a 12 -h light/12-h dark cycle with free access to food and water. MDA-MB-231 cells grown at logarithm phase were harvested, washed and resuspended in PBS at $3 \times 10^{7}$ cells $/ \mathrm{ml}$. A total of $200 \mu \mathrm{l}$ cell suspension $\left(5 \times 10^{6}\right.$ cells) was implanted into the breast (mammary fad pat) of each mouse every other day for 6 days. For tumor growth analysis, tumor volume was calculated according to the formula: $\mathrm{V}=1 / 2 \mathrm{ab}^{2}$, where $\mathrm{a}$ and $\mathrm{b}$ stand for the length and the width of tumor measured with sliding caliper, respectively. Adenovirus was not injected until tumor volume grew up to $50 \mathrm{~mm}^{3}$ (25). Tumor-bearing mice were randomly grouped into three groups ( $\mathrm{n}=6$ /group) for Ad-Vector, Ad-ROD1 and Ad-shROD1. All processes were carried out in a biosafety cabinet (Thermo Fisher Scientific, Inc.). After 15 days, the mice were sacrificed using cervical dislocation and the tumors from tumor-bearing mice were harvested.

Additionally, female TA2 mice with spontaneous breast cancer were obtained from Tianjin Medical University (Tianjin, China) and the mean weight of these mice were $18.11 \mathrm{~g}$. TA2 mice are considered as animal model of breast cancer and in the present study, 10 TA2 mice were prepared/group. The incidence of spontaneous breast cancer in TA2 mice is greater than $80 \%$ in the absence of any external chemical stimuli (26,27). The tumors appeared at the age of 360 days. These mice were sacrificed using cervical dislocation. Breast cancer tissues and normal mammary tissues were fixed in $10 \%$ formalin buffer at $4^{\circ} \mathrm{C}$ for $24 \mathrm{~h}$. Tumors without necrosis of 6 mice were employed for further analysis.

The present study was approved by the Animal Care and Protection Committee of the Laboratory Animal Center of Soochow University (SYXK 2014-0030; Jiangsu, China). 
A

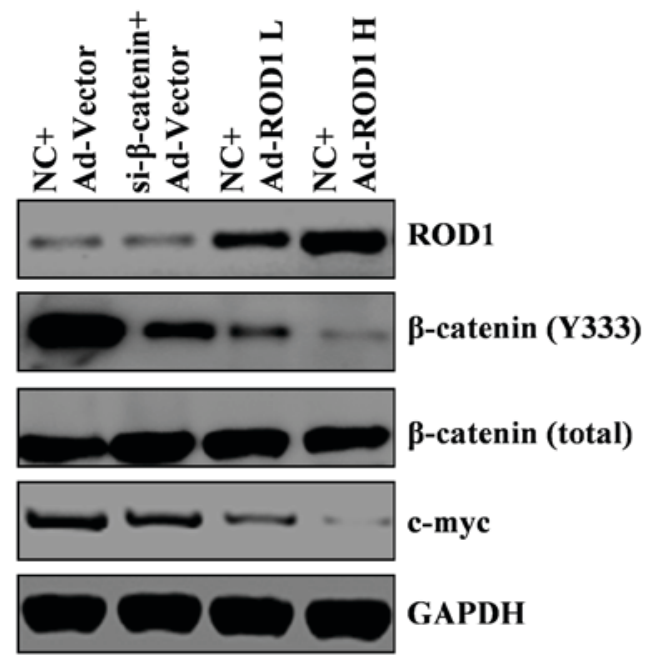

C

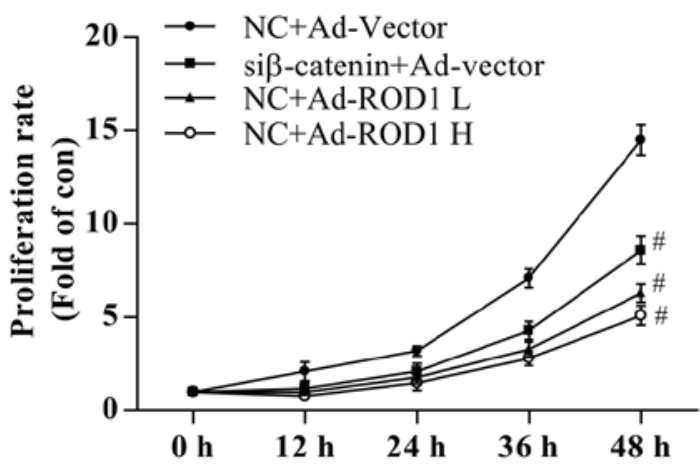

B

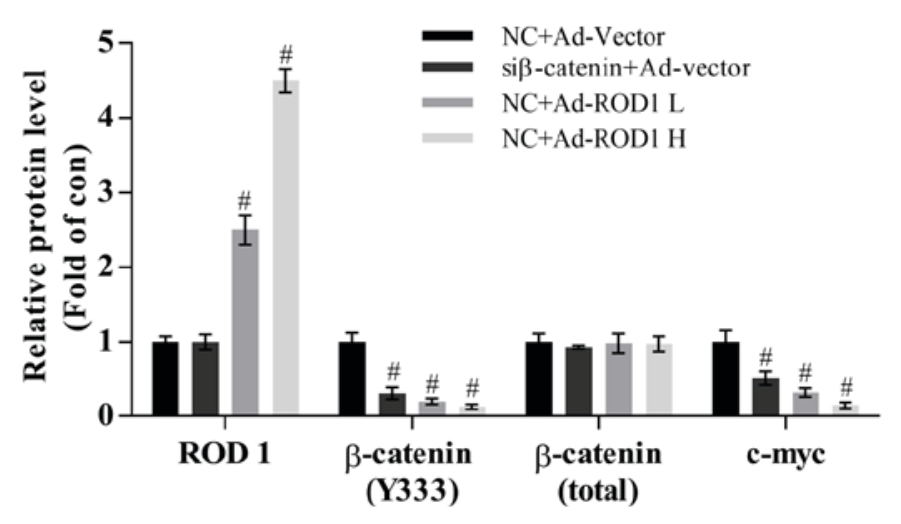

$\mathbf{D}$

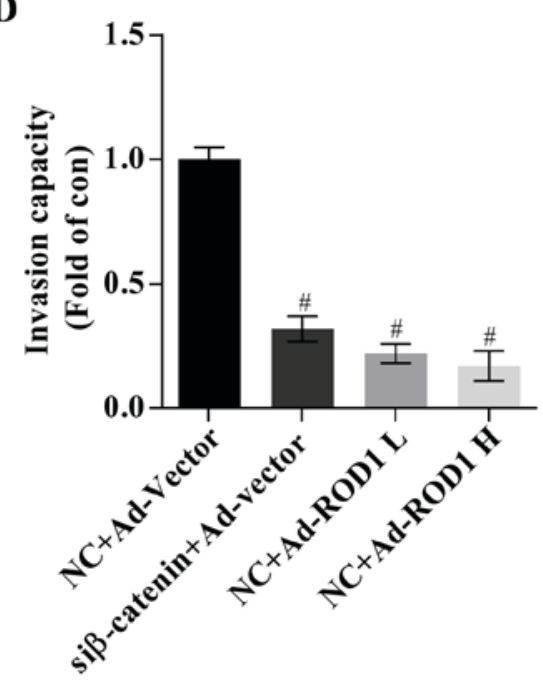

Figure 3. Wnt/ $\beta$-catenin signaling pathway serves an important role in cell growth and invasion of MDA-MB-231 cells. (A) Western blotting and (B) quantification of protein levels of ROD1 and $\beta$-catenin in MDA-MB-231 cells transfected with Ad-ROD1 and $\beta$-catenin siRNA. NC+Ad-Vector was considered as the control. NC+Ad-ROD1L group was the low $\left(2 \times 10^{2}\right.$ plaque forming units) and NC+Ad-ROD1 $\mathrm{H}$ was the high dose group ( $2 \times 10^{3}$ plaque forming units) of Ad-ROD1 adenovirus, respectively. (C) A proliferation assay was performed using MDA-MB-231 cells and MDA-MB-231 cells were classified as four groups: NC+Ad-vector, si $\beta$-catenin+Ad-vector, NC+Ad-ROD1L and NC+Ad-ROD1 H. (D) Transwell assay was carried out to examine the invasiveness in MDA-MB-231 cells. ${ }^{~} \mathrm{P}<0.05$ vs. the control. All experiments were replicated three times. Ad, adenovirus; ROD1, regulator of differentiation 1; si, small interference; NC, siRNA negative control.

Statistical analysis. All data are expressed as the mean \pm standard deviation. Comparisons between two groups were performed using Student's t-test. Comparisons among multiple groups were performed with one-way analysis of variance followed by Tukey's honestly significant difference test. Statistical analyses were conducted using SPSS 17.0 software (SPSS, Inc., Chicago, IL, USA). $\mathrm{P}<0.05$ was considered to indicate a statistically significant difference.

\section{Results}

ROD1 expression is downregulated in breast cancer cells. To study the potential role of ROD1 in the invasion of breast cancer cells, its expression in HMC, MCF10A, MCF-7 and MDA-MB-231 cells was analyzed by western blot analysis and RT-qPCR. HMC cells were used as control. The data demonstrated that ROD1 protein and mRNA expression levels were lower in cancer cells compared with that in the HMC cells. MDA-MB-231 cells exhibited the lowest expression of ROD1 (Fig. 1A-C). However, there was no difference in the expression of ROD1 between HMC and MCF10A cells $(\mathrm{P}>0.5)$. Notably, ROD1 was significantly reduced in tumor tissues as evaluated by western blot analysis (Fig. 1D and E) and RT-qPCR (Fig. 1F).

ROD1 inhibits proliferation and invasion in MDA-MB-231 cells. The effects of ROD1 in breast cancer cells were also investigated. Ad-ROD1 was used to overexpress ROD1 and Ad-shROD1 was used to knockdown ROD1 in MDA-MB-231 cells. In the present study, ROD1 was successfully overexpressed compared with Ad-Vector group) as evaluated by western blotting (Fig. 2A and B) and RT-qPCR (Fig. 2C). 


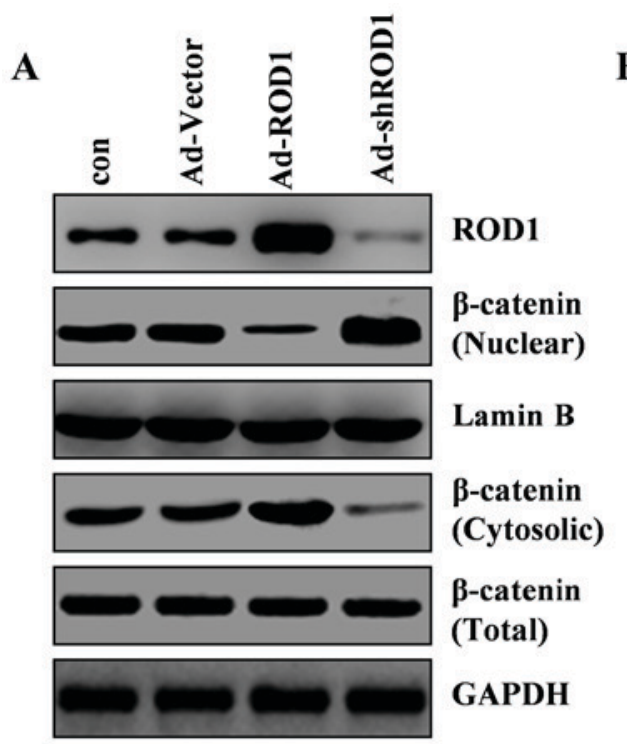

B

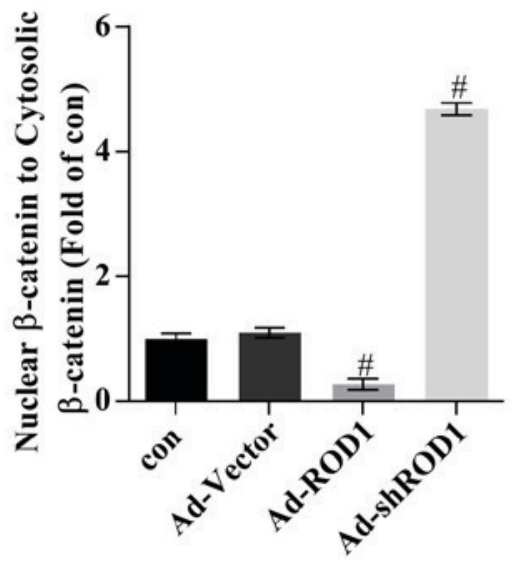

C

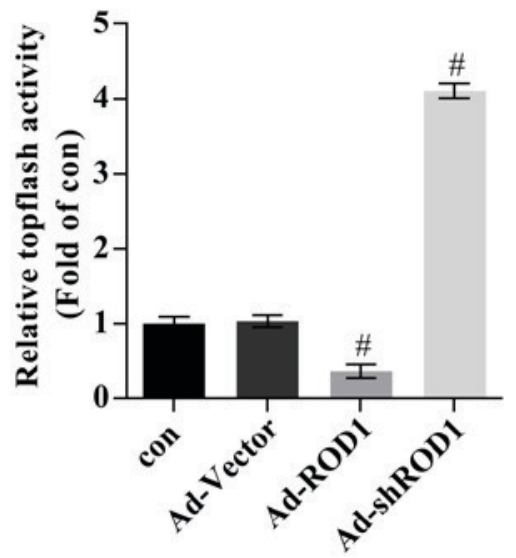

D

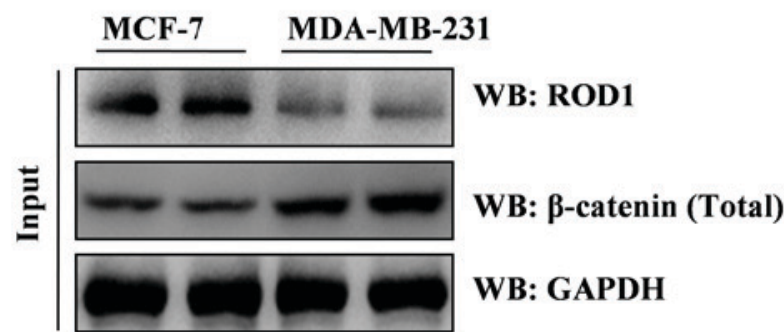

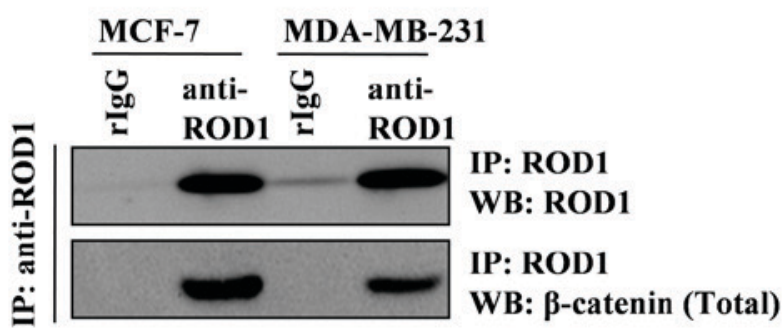

Figure 4. ROD1 inhibits translocation of $\beta$-catenin from cytosol to nucleus in MDA-MB-231 cells. (A and B) Western blotting demonstrated that the inhibition of ROD1 on cytosolic $\beta$-catenin compared with its (A) nuclear form and (B) quantification of it. For the cytosol, the data was normalized to GADPH and for the nucleus, the data was normalized to Lamin. (C) The TOP Flash/FOP Flash activity was analyzed by luciferase reporter assay. (D) Interaction of ROD1 with $\beta$-catenin detected by co-IP. All experiments were repeated three times. " $\mathrm{P}<0.05$ vs. con (control). Con, without adenovirus incubation; Ad, adenovirus; ROD1, regulator of differentiation 1; IP, immunoprecipitation; WB, western blotting; sh, short hairpin.

The 'con' group contained MDA-MB-231 cells that were not treated with Ad-Vector or other adenoviral vectors and the Ad-Vector group contained MDA-MB-231 cells that were transfected with Ad-Vector adenoviruses. Breast cancer cells transfected with Ad-ROD1 exhibited a significantly lower proliferation rate than the control as assessed by CCK- 8 assay following infection for 24, 36 and $48 \mathrm{~h}$ (Fig. 2D). The data are presented as folds of the starting time in each group relative to the control. Overexpression of ROD1 resulted in a significant reduction in the invasion rate of MBA-MB-231 cells as determined by a Transwell assay (Fig. 2E). Cells infected with Ad-shROD1 exhibited increased cell proliferation and invasion capacity in vitro (Fig. 2D and E).

Involvement of Wnt/ $\beta$-catenin pathway in proliferation and invasion of $M D A-M B-231$ cells. It has been reported that activation of the $\mathrm{Wnt} / \beta$-catenin signaling pathway serves an essential role in breast cancer (2-4). In the present study, it was demonstrated that ROD1 may reduce $\beta$-catenin (Y333) and c-Myc protein expression levels in a dose-dependent manner (Fig. 3A and B). C-Myc is a target of Wnt/ $\beta$-catenin and often promotes cancer occurrence (21). Notably, it was demonstrated that $\beta$-catenin was successfully significantly knocked down as demonstrated by western blot analysis $(\mathrm{P}<0.05$; Fig. 3A and $\mathrm{B})$. Knockdown of $\beta$-catenin suppressed proliferation and invasion of MDA-MB-231 cells (Fig. 3C and D). Therefore, these results indicate that $\mathrm{wnt} / \beta$-catenin pathway is involved in development of breast cancer.

ROD1 inhibits migration of $\beta$-catenin from cytosol to nuclei through interaction with $\beta$-catenin. In the present study, the results revealed that ROD1 significantly inactivated Wnt/ $\beta$-catenin signaling pathway. Western blotting and TOPflash luciferase assay demonstrated that $\beta$-catenin was inactivated and translocated less into the nucleus in response to Ad-ROD1, whereas Ad-shROD1 promoted $\beta$-catenin translocation into the nucleus of MDA-MB-231 cells (Fig. 4A-C). Notably, the data indicated that ROD1 interacted with $\beta$-catenin in MDA-MB-231 and MCF-7 cells. Furthermore, ROD1 may interact with $\beta$-catenin in MCF-7 and MDA-MB-231 cells (Fig. 4D). These data indicated that ROD1 interacted with $\beta$-catenin leading to a reduction of nuclear $\beta$-catenin protein levels and suppression of $\mathrm{Wnt} / \beta$-catenin signaling pathway in cancer cells.

ROD1 suppresses tumor growth in nude mouse xenograft model. The inhibition of ROD1 on tumor growth was investigated in a nude mouse xenograft model. $\beta$-catenin (Y333) was commonly located in nucleus. Firstly, $\beta$-catenin (Y333) in tumor tissues was downregulated by overexpression of ROD1 
A

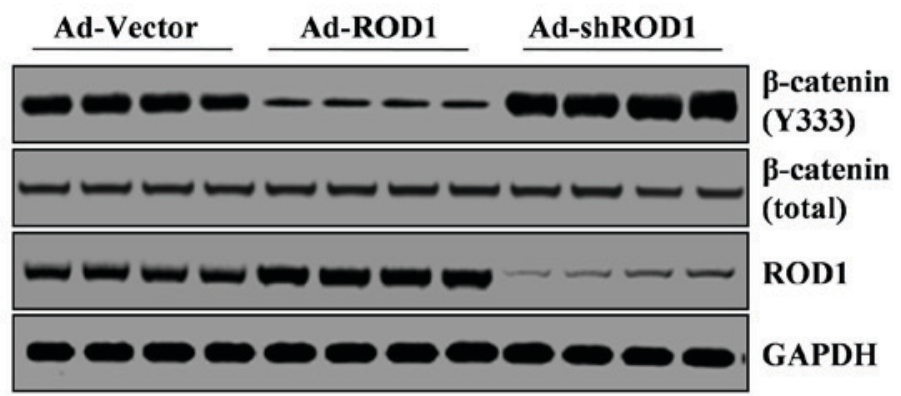

C

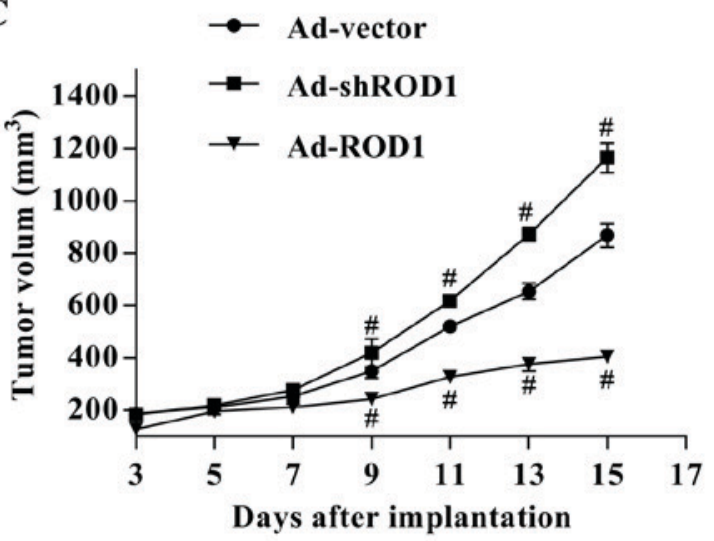

E

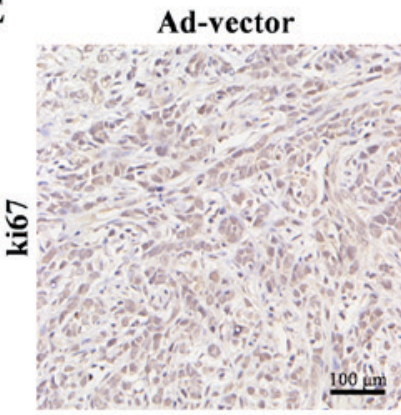

Ad-ROD1

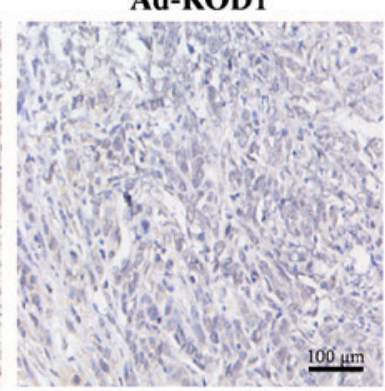

D

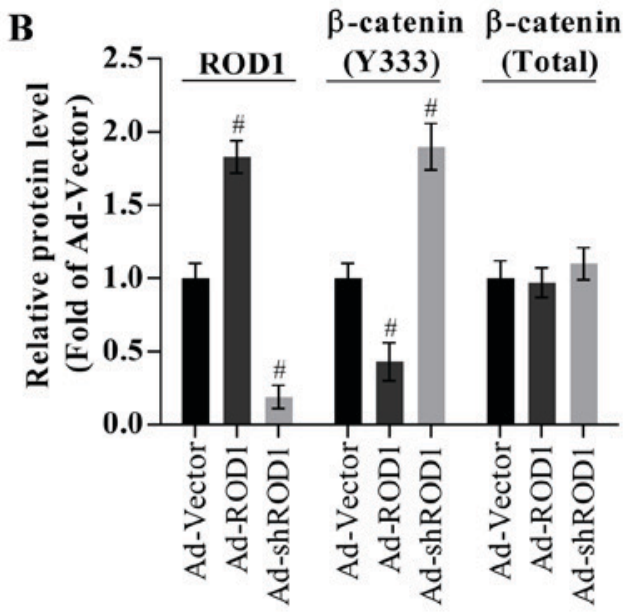

Ad-Vector

Ad-shROD1

Ad-ROD1
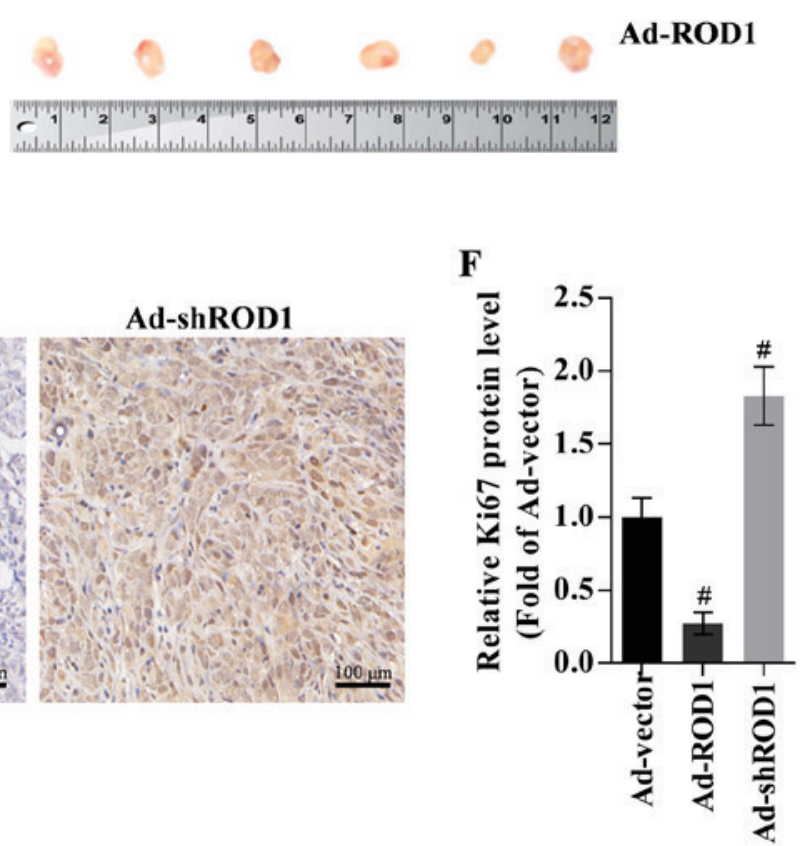

Figure 5. ROD1 suppresses tumor growth in a nude mouse xenograft model. (A) Western blot analysis of $\beta$-catenin (Y333) in tumor tissues and (B) quantification of its expression levels. (C) Tumor regression observed in xenografts treated with Ad-vector, Ad-ROD1 and Ad-shROD1. (D) Representative images of tumors taken on day 15 following inoculation of MDA-MB-231 cells. The revealed no significant difference in tumor growth, suggesting that tumors were induced by continued infection of MDA-MB-231 cells. Analysis of Ki67 expression in tumor tissues, as detected by (E) immunohistochemistry and (F) quantified. ${ }^{\#} \mathrm{P}<0.05$ vs. Ad-Vector. Ad, adenovirus; ROD1, regulator of differentiation 1; sh, short hairpin. Scale bars, $100 \mu \mathrm{m}$ (Fig. $5 \mathrm{E}$ ).

(Ad-ROD1) but was upregulated by knockdown of ROD1 (Ad-shROD1) as indicated in Fig. 5A and B. In the present study, total $\beta$-catenin protein was used as an internal control for nuclear $\beta$-catenin (Y333), and GAPDH was used as an internal control for total $\beta$-catenin and ROD1 (Fig. 5A and B). Notably, in the control group (Ad-Vector group), the volume of harvested tumors on the third day was $\sim 4.64$-fold larger, compared with that on starting day with injection of Ad-Vector. In the Ad-ROD1 and Ad-shROD1 groups, the volume of harvested tumors on the third day was 3.16-fold and 6.33-fold larger, compared with that on starting day with injection of the adenoviruses. Compared with the Ad-vector group, Ad-ROD1 demonstrated an inhibitory effect $(\mathrm{P}<0.05)$ on tumor growth (Fig. 5C and D). Notably, Ki67 was significantly downregulated by Ad-ROD1 $(\mathrm{P}<0.05)$ and was significantly upregulated by Ad-shROD1 in cancer tissues $(\mathrm{P}<0.05)$ (Fig. 5E and $\mathrm{F})$.

\section{Discussion}

The Wnt/ $\beta$-catenin signaling pathway serves a vital role in stem cell self-renewal and differentiation $(28,29)$, as well as tumorigenesis (22-24). Wnt/ $\beta$-catenin signaling pathway is 
activated in various types of cancer resulting in abnormal accumulation of $\beta$-catenin in the nucleus, where $\beta$-catenin interacts with the transcription factor TCF/LEF (22-24). Finally, this interaction promotes the expression of target genes such as c-Myc and cyclin (22-24). Additionally, increased $\beta$-catenin activity was demonstrated to be associated with the poor prognosis in patients with breast cancer $(4,5)$. Thus, inhibition of Wnt/ $\beta$-catenin signaling pathway may be a promising treatment of breast cancer.

ROD1 was initially regarded as an inhibitor of K562 cell differentiation (11). ROD1 also may promote proliferation but inhibit the differentiation of human gastric cancer MKN45 cells (16). However, the role of ROD1 in breast cancer remains unknown. In the present study, the molecular mechanism of inhibition of breast cancer cell growth mediated by ROD1 was investigated. The results revealed that ROD1 inhibited proliferation and migration of MBA-MB-231 cells. The results demonstrated that the expression of ROD1 was reduced in breast cancer cells and tumor tissues. Additionally, ROD1 may inhibit the invasion of MBA-MB-231 cells. Previous studies $(11,16)$ demonstrated that ROD1 may be a promising suppressor in breast cancer, however further studies are needed to confirm the results of the present study.

The molecular mechanism underlying ROD1-mediated inhibition of the invasion of breast cancer cells was also investigated. It has been reported that the transcriptional activity of $\beta$-catenin is determined by its protein level and its cellular localization (30). In the present study, it was demonstrated that ROD1 may inhibit translocation of $\beta$-catenin into the nucleus leading to decreased expression of its downstream targets, including c-Myc, in a dose-dependent manner in MDA-MB-231 cells. Additionally, it was demonstrated that ROD1 suppressed the migration of $\beta$-catenin from cytosol into the nucleus as assessed using a TOPflash luciferase assay. Together, these data indicated that ROD1 may suppress the invasive ability of breast cancer through its interaction with $\beta$-catenin by inhibiting $\beta$-catenin migration into the nucleus.

In order to explore the inhibitory effect of ROD1 on the growth of MDA-MB-231 cells in vivo, these cells were implanted into nude mice. It was demonstrated that Ad-ROD1 inhibited $\beta$-catenin migration into nuclei by reducing phosphorylated $\beta$-catenin (Y333) in tumor tissues, thus leading to tumor suppression. Additionally, it was demonstrated that Ad-shROD1 may induce tumor growth and $\beta$-catenin phosphorylation (Y333). Furthermore, Ki67 was downregulated by Ad-ROD1 and was upregulated by Ad-shROD1 in tumor tissues.

Taken together, ROD1 may illustrate its anticancer effect on breast cancer cells invasion through interacting with $\beta$-catenin by inhibiting its activity and suppressing its migration to the nucleus. The present study demonstrated that ROD1 may be a tumor suppressor of breast cancer.

\section{Acknowledgements}

Not applicable.

\section{Funding}

No funding was received.

\section{Availability of data and materials}

The datasets used and/or analyzed during the current study are available from the corresponding author on reasonable request.

\section{Authors' contributions}

YZ and XZ designed the experiment. YZ, HZ, EW, LH, RY and $\mathrm{YM}$ performed the experiment. $\mathrm{YZ}$ and $\mathrm{HZ}$ processed the data and $\mathrm{XZ}$ wrote the manuscript. All authors read and approved the final manuscript.

\section{Ethics approval and consent to participate}

The present study was approved by the Animal Care and Protection Committee of the Laboratory Animal Center of Soochow University (approval no. SYXK 2014-0030; Jiangsu, China).

\section{Consent for publication}

Not applicable.

\section{Competing interests}

The authors declare that they have no competing interests.

\section{References}

1. DeSantis C, Ma JM, Bryan L and Jemal A: Breast Cancer Statistics, 2013. CA Cancer J Clin 64: 52-62, 2014.

2. Polakis P: The oncogenic activation of beta-catenin. Curr Opin Genet Dev 9: 15-21, 1999.

3. Howe LR and Brown AM: Wnt signaling and breast cancer. Cancer Biol Ther 3: 36-41, 2004.

4. Incassati A, Chandramouli A, Eelkema R and Cowin P: Key signaling nodes in mammary gland development and cancer: $\beta$-catenin. Breast Cancer Res 12: 122010.

5. Lin SY, Xia WY, Wang JC, Kwong KY, Spohn B, Wen Y, Pestell RG and Hung MC: beta-catenin, a novel prognostic marker for breast cancer: Its roles in cyclin D1 expression and cancer progression. Proc Natl Acad Sci USA 97: 4262-4266, 2000.

6. Behrens J: Control of beta-catenin signaling in tumor development. Ann Ny Acad Sci 910: 21-35, 2000.

7. Holland JD, Klaus A, Garratt AN and Birchmeier W: Wnt signaling in stem and cancer stem cells. Curr Opin Cell Biol 25: 254-264, 2013.

8. Turashvili G, Bouchal J, Burkadze G and Kolar Z: Wnt signaling pathway in mammary gland development and carcinogenesis. Pathobiology 73: 213-223, 2006.

9. Verras M and Sun ZJ: Roles and regulation of Wnt signaling and beta-catenin in prostate cancer. Cancer Lett 237: 22-32, 2006.

10. Amado NG, Fonseca BF, Cerqueira DM, Neto VM and Abreu JG: Flavonoids: Potential Wnt/beta-catenin signaling modulators in cancer. Life Sci 89: 545-554, 2011.

11. Yamamoto H, Tsukahara K, Kanaoka Y, Jinno S and Okayama H: Isolation of a mammalian homologue of a fission yeast differentiation regulator. Mol Cell Biol 19: 3829-3841, 1999.

12. Spellman R, Llorian M and Smith CW: Crossregulation and functional redundancy between the splicing regulator PTB and its paralogs nPTB and ROD1. Mol Cell 27: 420-434, 2007.

13. Maniatis T and Tasic B: Alternative pre-mRNA splicing and proteome expansion in metazoans. Nature 418: 236-243, 2002.

14. Hagen RM and Ladomery MR: Role of splice variants in the metastatic progression of prostate cancer. Biochem Soc Trans 40: 870-874, 2012

15. Brazao TF, Demmers J, van IJcken W, Strouboulis J, Fornerod M, Romão L and Grosveld FG: A new function of ROD1 in nonsense-mediated mRNA decay. FEBS Lett 586: 1101-1110, 2012. 
16. Chen B, Zhao AG, Shao J, Mu XY, Jiang L and Liu JW: The effects of PTBP3 silencing on the proliferation and differentiation of MKN45 human gastric cancer cells. Life Sci 114: 29-35, 2014.

17. Livak KJ and Schmittgen TD: Analysis of relative gene expression data using real-time quantitative PCR and the 2(-Delta Delta C(T)) method. Methods 25: 402-408, 2001.

18. Luo J, Deng ZL, Luo X, Tang N, Song WX, Chen J, Sharff KA, Luu HH, Haydon RC, Kinzler KW, et al: A protocol for rapid generation of recombinant adenoviruses using the Ad Easy system. Nat Protoc 2: 1236-1247, 2007.

19. Lv K, Guo YJ, Zhang YL, Wang K, Li K, Zhu Y and Sun S: Transient inhibition of foot-and-mouth disease virus replication by siRNAs silencing VP1 protein coding region. Res Vet Sci 86: 443-452, 2009.

20. Anderson RD, Haskell RE, Xia H, Roessler BJ and Davidson BL: A simple method for the rapid generation of recombinant adenovirus vectors. Gene Ther 7: 1034-1038, 2000.

21. Lu FI, Sun YH, Wei CY, Thisse C and Thisse B: Tissue-specific derepression of TCF/LEF controls the activity of the Wnt/ $\beta$-catenin pathway. Nat Commun 5: 5368, 2014

22. Gaspar C and Fodde R: APC dosage effects in tumorigenesis and stem cell differentiation. Int J Dev Biol 48: 377-386, 2004.

23. Chen GP, Shukeir N, Potti A, Sircar K, Aprikian A, Goltzman D and Rabbani SA: Up-regulation of Wnt-1 and $\beta$-catenin production in patients with advanced metastatic prostate carcinoma-Potential pathogenetic and prognostic implications. Cancer 101: 1345-1356, 2004.
24. Yang F, Zeng Q, Yu G, Li S and Wang CY: Wnt/beta-catenin signaling inhibits death receptor-mediated apoptosis and promotes invasive growth of HNSCC. Cell Signal 18: 679-687, 2006.

25. Fiebig HH, Berger DP, Winterhalter BR and Plowman J: In vitro and In vivo evaluation of Us-Nci compounds in human tumor xenografts. Cancer Treat Rev 17: 109-117, 1990.

26. Zhang D, Fei F, Li S, Zhao Y, Yang Z, Qu J, Zhang X, Yin Y and Zhang $S$ : The role of $\beta$-catenin in the initiation and metastasis of TA2 mice spontaneous breast cancer. J Cancer 8: 2114-2123, 2017.

27. Sun B, Zhang S, Zhang D, Liu Y, Li Y, Rong Z, Zhu Y and Jia X: Clusterin is associated with spontaneous breast cancer in TA2 mice. FEBS Lett 581: 3277-3282, 2007.

28. Lindvall C, Evans NC, Zylstra CR, Li Y, Alexander CM and Williams BO: The Wnt signaling receptor Lrp5 is required for mammary ductal stem cell activity and Wnt1-induced tumorigenesis. J Biol Chem 281: 35081-35087, 2006.

29. Reya $\mathrm{T}$ and Clevers $\mathrm{H}$ : Wnt signalling in stem cells and cancer. Nature 434: 843-850, 2005

30. Rosano L, Cianfrocca R, Spinella F, Di Castro V, Nicotra MR, Lucidi A, Ferrandina G, Natali PG and Bagnato A: Acquisition of chemoresistance and EMT phenotype is linked with activation of the endothelin A receptor pathway in ovarian carcinoma cells. Clin Cancer Res 17: 2350-2360, 2011. 